\title{
Prospective association between dietary patterns and BMI Z-score in Brazilian adolescents
}

\author{
Adélia CP Arruda Neta ${ }^{1, *} \odot$, José Cazuza Farias Junior ${ }^{2}$, Flávia EL Lima Ferreira ${ }^{3}$ and \\ Dirce M Marchioni ${ }^{1}$ (e) \\ 'Department of Nutrition, School of Public Health, University of Sao Paulo, Av. Dr. Arnaldo, 715 - Cerqueira César, \\ São Paulo-SP 01 246-904, Brazil: ${ }^{2}$ Department of Physical Education, Federal University of Paraiba, João Pessoa, PB, \\ Brazil: ${ }^{3}$ Department of Nutrition, Federal University of Paraiba, João Pessoa, PB, Brazil
}

Submitted 28 May 2020: Final revision received 5 January 2021: Accepted 18 January 2021: First published online 21 January 2021

\begin{abstract}
Objective: To identify dietary patterns and prospectively evaluate their influence on the BMI $Z$-score of adolescents.

Design: A longitudinal study, using data from the Longitudinal Study on Sedentary Behavior, Physical Activity, Eating Habits and Adolescent Health - LONCAAFS. Setting: To obtain data on food consumption, a 24-h recall survey was conducted; a second 24-h recall was applied to $30 \%$ of the sample in all waves. Dietary patterns were identified by exploratory factor analysis using principal components. BMI $Z$-score was determined according to the recommendation of the WHO, based on the BMI for age and sex. Socio-economic data, sedentary behaviour and physical activity level were obtained. Associations between BMI $Z$-score and dietary patterns and between BMI $Z$-score and variables of interest were determined using generalised estimating equations.

Participants: Totally, 1431 adolescents were assessed in 2014, 1178 in 2015, 959 in 2016 and 773 in 2017, belonging to the public schools of João Pessoa, Northeast Brazil. Results: Three dietary patterns were identified throughout the study: 'traditional', 'snacks' and 'Western'. The 'Western' dietary pattern was positively associated with BMI $Z$-score $(\beta=0.025 ; 95 \%$ CI 0.002, 0.048), regardless of sex and physical activity level, prospectively.

Conclusion: A dietary pattern composed of foods with high energy density, high fat and sugars, and low fibre influences the BMI $Z$-score of adolescents over time.
\end{abstract}

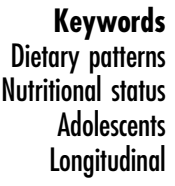

Overweight in adolescence is considered a public health problem because of the immediate implications on physical, social and mental health, and long-term effects, such as the development of non-communicable chronic diseases in adulthood ${ }^{(1)}$. The prevalence of overweight in Brazilian adolescents is increasing. According to a previous study on the cardiovascular risk factors in adolescents, $25.5 \%$ of the Brazilian adolescents are overweight ${ }^{(2)}$. Several epidemiological studies have demonstrated the importance of dietary habits in the development of overweight and disease ${ }^{(3-5)}$. Inadequate dietary habits may favour the weight gain and lead to the development of overweight ${ }^{(6)}$.

Most dietary habits are formed and established during adolescence. This is considered a risk period for the development of overweight ${ }^{(7)}$. Diet is a process that involves the consumption of different foods or food groups simultaneously, with a complex interaction between nutrients; a study on dietary patterns will help determine the effect of the combination of foods and nutrients on health outcomes and disease ${ }^{(8,9)}$.

Therefore, identifying the dietary patterns of adolescents and their longitudinal association with nutritional status is important to determine the impact of dietary habits on nutritional status, over time, and to ensure that interventions and policies in the prevention of excess weight are developed. However, studies that assess the dietary patterns and nutritional status of adolescents in Brazil are limited, and most have a cross-sectional design ${ }^{(10,11)}$. No previous longitudinal studies have examined the impact of dietary patterns on the nutritional status of adolescent students in Brazil.

Accordingly, this study aimed to identify dietary patterns and evaluate their influence on the nutritional status of adolescents participating in a longitudinal study in a city of Northeast Brazil. 


\section{Methods}

A longitudinal epidemiological study was conducted using the data from the Longitudinal Study on Sedentary Behavior, Physical Activity, Dietary Habits and Health of Adolescents (LONCAAFS), which started in 2014. The LONCAAFS was conducted in sixth-grade adolescents, aged 10 to 14 years (mean 12.02 years), from the public schools (municipal and state) in the municipality of João Pessoa. The sample was monitored annually until 2017 in order to analyse the inter-relationships between sedentary behaviour, physical activity, diet and health.

The following parameters were taken into account to calculate the sample size: size of the reference population (9520 sixth-grade adolescents); the prevalence of the outcome equal to $50 \%$, to determine the largest possible sample size with the same percentage error; a CI of $95 \%$, acceptable absolute error of four percentage points, and a design effect equal to 2. Based on these parameters, the minimum sample size was 1130 adolescents. This number was increased by $40 \%$ to compensate for possible losses and refusals, resulting in a final sample of 1582 adolescents. Subsequently, the sample power was calculated for the present study, which was $99 \%$.

Selection of sample was performed using single-stage cluster sampling: 28 schools (14 municipal and 14 state schools) were selected, proportionally distributed according to the geographic location and the number of students enrolled in the sixth grade in 2014. In the selected schools, all students in the sixth-grade classes were invited to participate in the study.

Adolescents outside the age group of interest in the study (below 10 and above 14 years in 2014), with a disability that prevented or limited the practice of physical activity or response to the questionnaire, who were pregnant, whose anthropometric measurements (height and BMI) were not obtained, and who did not respond to the 24-h recall survey, were excluded.

In 2014, the study sample initially consisted of 1431 adolescents. Between 2014 and 2015, approximately $17 \%$ of the sample were lost to follow-up; between 2015 and 2016, 15\%; and between 2016 and 2017, 13\%. Approximately $46 \%$ of the total sample were lost to follow-up at the end of the 4-year study period (see online Supplemental Table 1). At the end of the study, in 2017, the sample only consisted of 773 adolescents. There was no statistical difference between the adolescents who remained and those who left the study.

\section{Data collection}

Data collection was carried out between February and December of each year by a previously trained team, composed of undergraduate and graduate students and professionals in the areas of nutrition and physical education. The socio-demographic data, level of physical activity and sedentary behaviour were obtained through a faceto-face-interview held during the class shift in school using a questionnaire and had a mean duration of $50 \mathrm{~min}$. Data collection was performed individually, in a reserved room at the school for this purpose only.

\section{Dietary assessment}

Food consumption was measured using 24-h dietary recall. The adolescents were asked about all foods and beverages consumed in the last $24 \mathrm{~h}$, form of preparation, brand (industrialised foods) and weight or size of portions, in grams, ounces or household measures. The second 24-h dietary recall was conducted in $30 \%$ of the total sample, each year, in order to reduce the intrapersonal variability of diet and increase the accuracy of the estimation of dietary intake, respecting the seasonal dietary variation at different times of the year and increasing the randomisation of the several weekdays in a more equitable way possible ${ }^{(12)}$. The data were tabulated in the 'Virtual Nutri Plus' software, and regular intake of energy and nutrients was estimated using the multiple source method. This method is suitable to estimate individual usual intake in the case of repeated measurements and a defined time period.

\section{Dietary patterns}

The foods were divided into fourteen groups, according to the correlation (correlation matrix) and/or similarities in nutritional composition: basic foods (rice, couscous and cassava), beans, fruits and vegetables, meats, processed meats, butters and margarines, breads and breakfast cereals, sweets, pastries, sweetened drinks, dairy products, cheeses, coffee and tea, and soups (Table 1). The items in the 24-h dietary recall consumed by less than $5 \%$ of the sample were excluded from the analysis, each year. The habitual consumption of food groups was estimated using the multiple source method.

Dietary patterns were identified using exploratory factor analysis by principal components. The adequacy of the data for factor analysis was verified by the KaiserMeyer-Olklin test and Bartlett's sphericity test ${ }^{(13)}$. The eigenvalue value (values above 1.0), eigenvalue graph (Scree plot) and the interpretability of the patterns were the criteria used to identify the number of patterns to be retained $^{(13)}$. Varimax orthogonal rotation was performed to generate uncorrelated factors to facilitate factor interpretation. The highest factor load values were taken into account to identify the patterns found ${ }^{(13)}$. These procedures were performed each year, separately, to verify if the eating patterns were similar throughout the years ${ }^{(14,15)}$. Variables with factor loadings $\geq 0.30$ or $\leq-0.30$ were considered important for factor interpretability. Since the patterns were similar throughout the study (see online Supplemental Table 2), for the analysis of prospective association, we calculated the factor scores for each dietary pattern at 
Table 1 Structures of dietary patterns identified by factorial analysis of adolescents in public schools in João Pessoa during the LONCAAFS study, from 2014 to $2017 \dagger$,

\begin{tabular}{|c|c|c|c|c|}
\hline \multirow[b]{2}{*}{ Groups } & \multirow[b]{2}{*}{ Description } & \multicolumn{3}{|c|}{2014 loadings§ } \\
\hline & & $\begin{array}{l}\text { Traditional } \\
\text { pattern }\end{array}$ & $\begin{array}{l}\text { Snacks } \\
\text { pattern }\end{array}$ & $\begin{array}{l}\text { Western } \\
\text { pattern }\end{array}$ \\
\hline Basic food & Rice, cassava, couscous, yam, and other roots and tubers & 0.73 & 0.03 & 0.01 \\
\hline Beans & Beans and food based on beans & 0.55 & 0.16 & 0.08 \\
\hline Fruit and vegetables & $\begin{array}{l}\text { Fruits, fruit salad, unsweetened natural juices, leafy } \\
\text { vegetables and vegetables }\end{array}$ & 0.08 & -0.08 & 0.14 \\
\hline Meat & Beef cattle, swine, poultry and meat preparations & 0.71 & -0.03 & 0.09 \\
\hline Processed meats & Turkey breast, ham, mortadella and sausage & -0.24 & 0.34 & 0.24 \\
\hline Butters and margarines & Butters and margarines & $0 \cdot 10$ & 0.54 & -0.23 \\
\hline $\begin{array}{l}\text { Breads, biscuits and } \\
\text { breakfast cereals }\end{array}$ & $\begin{array}{l}\text { White and integral breads, toast, breakfast cereals, } \\
\text { and salted biscuits }\end{array}$ & 0.01 & 0.83 & 0.08 \\
\hline Sweets & $\begin{array}{l}\text { Cakes, desserts, cookies, filled biscuits, chocolate } \\
\text { and sweets }\end{array}$ & 0.05 & -0.08 & 0.52 \\
\hline Pastries and snacks & $\begin{array}{l}\text { Fried Potatoes, hot dog, hamburger, pizza, sandwiches, } \\
\text { fried and baked snacks, and chips }\end{array}$ & -0.28 & $-0 \cdot 15$ & 0.41 \\
\hline Sugary drinks & $\begin{array}{l}\text { Soft drinks, industrialised juices, and sweetened natural } \\
\text { juices }\end{array}$ & $0 \cdot 16$ & 0.07 & 0.75 \\
\hline Milks and yogurts & $\begin{array}{l}\text { Milk and yoghurt (whole and skimmed milk), and } \\
\text { yogurt-based dairy drinks }\end{array}$ & -0.02 & 0.03 & 0.17 \\
\hline Cheeses & Cheeses and cheese preparations & -0.07 & 0.46 & 0.35 \\
\hline Coffee and tea & Coffee, coffee, and tea drinks & 0.16 & 0.51 & -0.30 \\
\hline Soups & Soups and broths & -0.34 & -0.05 & $-0 \cdot 18$ \\
\hline
\end{tabular}

LONCAAFS, Longitudinal Study on Sedentary Behavior, Physical Activity, Dietary Habits and Health of Adolescents.

Bold values are significant $(P<0.05)$.

tKaiser-Meyer-Olkin Test $(\mathrm{KMO})=0.57$.

‡Explained variance $=0.35$

§Loadings in bold: $\geq 0.30$ or $\leq-0.30$.

the individual level in the follow-up years (2015-2017), adding the consumption, in grams, by group of food, weighted according to the absolute factorial loads of the base year (2014), allowing the same metric to be seen over time ${ }^{(14,15)}$. The factor scores were standardised, and the mean score of each factor was set to zero.

\section{Outcome assessment}

In order to assess the nutritional status each year, body weight, stature and waist circumference measurements were obtained, which were measured in triplicate by the same evaluator, following a standardisation ${ }^{(16)}$, and the average was used for posterior calculations. A digital scale with a precision of $100 \mathrm{~g}$ was used to measure weight, height was measured in centimetres using a portable stadiometer and a tape measure was used to measure waist circumference. BMI (body mass $(\mathrm{kg}) /$ height $\left(\mathrm{m}^{2}\right)$ ) was determined based on the body mass and height values, while $Z$-score values ((individual value - mean)/sD) were obtained following the criteria suggested by the $\mathrm{WHO}^{(17)}$. To classify waist circumference, the 90th percentile $(\mathrm{P})$ of the sample was used as cut-off point, and adolescents below and above the P90 were classified as 'normal' and 'altered', respectively. Waist height ratio was obtained by dividing the waist circumference and height of the adolescent and was then classified as 'normal' and 'altered' when the indicator was below and above the population average in the year, respectively.

\section{Covariate assessment}

The socio-demographic variables used in this study were sex (male and female), age (difference between the date of data collection each year and date of birth), skin colour (brown, black, white, yellow and other indigenous categories proposed by the Brazilian Institute of Geography and Statistics), education level of parents (elementary, high school or higher) and socio-economic status (methodology of the Brazilian Market Research Association), which considers the presence of material goods and monthly employee in the residence, as well as parental schooling, grouping people in the following classes: 'A/B', 'C' and 'D/E', with the latter being the least privileged classes ${ }^{(18)}$.

The level of physical activity was measured using the Physical Activity Questionnaire for Adolescents ${ }^{(19,20)}$. The adolescents reported if, in the week prior to data collection, they had practised at least $10 \mathrm{~min}$ or had not practised at all, performed 19 types of physical activities of moderate to vigorous intensity, plus active displacement, in addition to providing the frequency and duration of practice of each activity. Adolescents were classified as physically active when they practised $420 \mathrm{~min}$ of physical activity or more per week ${ }^{(21)}$.

Sedentary behaviour was assessed through the measurement of the average time spent on screen activities, such as watching television, using the computer and tablet, and playing videogames, separately for weekdays and weekends. The arithmetical average was calculated by multiplying the average time in weekdays by five and 
weekends by two, and the results were divided by seven to obtain the mean time per day $(\mathrm{h} / \mathrm{d})$ of sedentary behaviour. A cut-off point for more than $2 \mathrm{~h} / \mathrm{d}$ was used to define sedentary behaviour ${ }^{(22)}$

\section{Statistical analysis}

In order to prospectively verify the association between dietary patterns and nutritional status, generalised estimating equation models were used to estimate regression parameters, especially when data were correlated. All generalised estimating equations models were run by the gaussian family and identity link function. After testing, no interaction between the sexes was verified, and there was no need for analysis stratification. In the adjusted model, the variables were selected using the stepwise method. The final equations were adjusted for sex, age, skin colour, mother's schooling, economic class, physical activity level, sedentary behaviour and total energy consumption. All analyses were performed using Stata 13.0 (StataCorp.LP).

\section{Results}

Three dietary patterns were identified, which remained similar throughout the study. The first pattern was positively associated with the consumption of basic food groups, beans and meat in all years of the study and negatively with soups. As this pattern characterises a typical Brazilian diet, it was categorised as 'traditional' pattern. The second dietary pattern was positively associated with the consumption of processed meats, butters and margarines, breads and breakfast cereals, cheeses, and coffee and teas in all years of the study; hence, it was categorised as 'snacks'. The third pattern identified was positively associated with consumption of sweets, pastries, sweetened drinks and cheeses in all years of the study but negatively correlated with consumption of coffee and teas and categorised as 'Western' pattern (Table 1).

The average BMI $Z$-score was higher in female adolescents in $2016(0 \cdot 34 ; P=0 \cdot 011)$ and in $2017(0 \cdot 26 ; P=0 \cdot 001)$ than in male adolescents and in adolescents with sedentary behaviour in $2014(0 \cdot 46 ; P=0.011)$, when compared with those without sedentary behaviour. There were no statistically significant differences in other variables over time (Table 2).

Table 3 shows the coefficients of the relationship between the BMI $Z$-score and, as an exposure, the adherence scores to each of the three patterns. The 'Western' dietary pattern was positively associated with the BMI $Z$-score (95\% CI 0.002, 0.048) over time, regardless of sex and level of physical activity. Thus, for each increment in the 'Western' pattern score, over time, there is an increase of 0.025 in the BMI $Z$-score (Table 3).

\section{Discussion}

The following three dietary patterns were identified at baseline, which remained similar throughout the study: 'traditional' pattern (basic foods, meat and beans), 'snacks' pattern (coffee and tea, butters and margarines, cheeses, and processed meats) and 'Western' pattern (sweetened drinks, sweets, pastries, cheeses, pastries and snacks). The 'Western' pattern correlated positively with the BMI $Z$-score over time in the adjusted model. These results suggest that such eating patterns are independently associated with BMI $Z$-score in Brazilian adolescents. This study, which included the participants of LONCAAFS study aged between 10 and 14 years, is the only study that prospectively examined the impact of dietary patterns on the BMI $Z$-score of adolescent students in Brazil.

The Northeast Brazilian has a very peculiar cuisine, and typical regional dishes are based on maize flour (couscous), roots and tubers (cassava, tapioca and yam); this is the reason why the study participant's diet is composed of basic foods, along with rice. The patterns identified in this study are similar to those reported by Alves et al., who analysed the data from the Study of Cardiovascular Risk in Adolescents. The dietary patterns of adolescents living in the Northeast region were as follows: 'bread and coffee' (bread, coffee, oil and fat, processed meat, and maize), 'unhealthy' (sweetened drinks, snacks, pasta, cakes and biscuits, and sweets and desserts) and 'traditional' pattern (rice, beans, meat and roots/tubers) ${ }^{(23)}$.

In Brazil, only a few studies have assessed the association between nutritional status and dietary patterns in adolescents. Borges et al., analysing adolescents participating in the 2008-2009 Household Budget Survey, identified four dietary patterns - 'traditional Brazilian', 'snacks', 'fast food' and 'breakfast with milk, fruits, and cereals' - finding a positive association between the dietary pattern of 'snacks' and 'fast food' and excess weight ${ }^{(10)}$. Cunha et al., who assessed the data from the National Human Food Survey in 2008-2009, identified three dietary patterns named 'traditional', 'bread and butter', and 'Western standard', indicating that the 'Western' eating pattern is associated with the BMI $Z$-score ${ }^{(11)}$.

Adherence to the 'Western' dietary pattern was directly associated with BMI $Z$-scores over time. Some previous longitudinal studies reported that higher adherence to dietary patterns similar to the 'Western' pattern had no significant association with increase in the BMI $Z$-score ${ }^{(14,24,25)}$.

However, in Europe, the Dortmund Nutritional and Anthropometric Longitudinally Designed (DONALD) study, which was conducted among children and adolescents aged between 3 and 18 years, found a small, but positive association between the consumption of these high-energy Western foods and body weight in boys ${ }^{(26)}$. The Avon Longitudinal Study of Parents and Children (ALSPAC) study found a 
Table 2 BMI Z-scores of adolescents in public schools in accordance with their characteristics during the LONCAAFS study, from 2014 to 2017

\begin{tabular}{|c|c|c|c|c|c|c|c|c|c|c|c|c|c|c|c|c|c|c|c|c|}
\hline \multirow[b]{2}{*}{ Variables } & \multicolumn{5}{|c|}{$2014(n 1431)$} & \multicolumn{5}{|c|}{$2015(n 1178)$} & \multicolumn{5}{|c|}{2016 (n 959) } & \multicolumn{5}{|c|}{$2017(n 773)$} \\
\hline & $n$ & $\%$ & Mean & SD & $P$ & $n$ & $\%$ & Mean & SD & $P$ & $n$ & $\%$ & Mean & SD & $P$ & $n$ & $\%$ & Mean & SD & $P$ \\
\hline \multicolumn{21}{|l|}{ Sex } \\
\hline Male & 673 & 47 & 0.42 & 1.36 & \multirow[t]{2}{*}{0.720} & 544 & 46 & 0.35 & 1.36 & \multirow[t]{2}{*}{0.653} & 451 & 47 & 0.13 & 1.38 & \multirow[t]{2}{*}{0.011} & 364 & 47 & -0.04 & 1.33 & \multirow[t]{2}{*}{0.001} \\
\hline Female & 758 & 53 & 0.39 & 1.22 & & 634 & 54 & 0.38 & 1.22 & & 508 & 53 & 0.34 & 1.21 & & 409 & 53 & 0.26 & 1.22 & \\
\hline \multicolumn{21}{|l|}{ Skin colour } \\
\hline White & 268 & 19 & 0.39 & 1.30 & \multirow[t]{2}{*}{0.870} & 184 & 16 & 0.36 & $1 \cdot 32$ & \multirow[t]{2}{*}{0.933} & 174 & 18 & 0.19 & $1 \cdot 21$ & \multirow[t]{2}{*}{0.600} & 136 & 18 & 0.02 & 1.07 & \multirow{2}{*}{0.320} \\
\hline Non-white & 1156 & 81 & 0.40 & 1.28 & & 994 & 84 & 0.37 & 1.28 & & 785 & 82 & 0.25 & 1.32 & & 637 & 82 & 0.14 & 1.32 & \\
\hline \multicolumn{21}{|l|}{ Mother's schooling } \\
\hline Up to elementary school & 482 & 41 & 0.37 & 1.26 & \multirow[t]{3}{*}{0.315} & 392 & 38 & 0.37 & 1.26 & \multirow[t]{3}{*}{0.934} & 295 & 35 & 0.28 & 1.29 & \multirow[t]{3}{*}{0.841} & 207 & 30 & 0.18 & 1.21 & \multirow[t]{3}{*}{0.695} \\
\hline Up to high school & 337 & 28 & 0.43 & 1.25 & & 280 & 27 & 0.41 & 1.30 & & 208 & 25 & 0.21 & 1.27 & & 185 & 27 & 0.08 & 1.26 & \\
\hline Completed high school or higher & 367 & 31 & 0.50 & 1.37 & & 365 & 25 & 0.38 & 1.27 & & 334 & 40 & 0.24 & 1.33 & & 303 & 43 & 0.11 & 1.32 & \\
\hline \multicolumn{21}{|l|}{ Economic class } \\
\hline Class $A / B$ & 463 & 37 & 0.51 & 1.30 & \multirow{3}{*}{0.056} & 132 & 12 & 0.43 & 1.27 & \multirow{3}{*}{0.835} & 111 & 13 & 0.21 & 1.31 & \multirow{3}{*}{0.932} & 242 & 34 & 0.08 & 1.29 & \multirow[t]{3}{*}{0.604} \\
\hline Class C & 737 & 58 & 0.39 & 1.28 & & 559 & 52 & 0.37 & 1.30 & & 479 & 55 & 0.26 & 1.31 & & 413 & 58 & 0.16 & 1.28 & \\
\hline Class D/E & 59 & 4.7 & 0.12 & 1.25 & & 378 & 35 & 0.41 & $1 \cdot 25$ & & 281 & 32 & 0.26 & 1.29 & & 61 & 8 & 0.03 & 1.04 & \\
\hline \multicolumn{21}{|l|}{ Physical activity } \\
\hline Active & 776 & 54 & 0.45 & 1.30 & 0.503 & 498 & 42 & 0.37 & 1.30 & 0.600 & 347 & 36 & 0.22 & 1.30 & 0.934 & 259 & 47 & 0.16 & 1.34 & 0.173 \\
\hline Inactive & 655 & 46 & 0.35 & $1 \cdot 27$ & & 680 & 58 & 0.36 & $1 \cdot 27$ & & 610 & 64 & 0.26 & 1.30 & & 514 & 53 & 0.09 & 1.25 & \\
\hline Sedentary behaviour & & & & & & & & & & & & & & & & & & & & \\
\hline$\leq 2 \mathrm{~h} / \mathrm{d}$ & 343 & 24 & 0.25 & $1 \cdot 24$ & 0.011 & 301 & 26 & 0.26 & 1.27 & 0.104 & 292 & 31 & 0.26 & 1.26 & 0.743 & 337 & 44 & 0.09 & 1.33 & 0.563 \\
\hline$>2 \mathrm{~h} / \mathrm{d}$ & 1088 & 76 & 0.46 & 1.30 & & 876 & 74 & 0.40 & 1.29 & & 662 & 69 & 0.24 & 1.32 & & 436 & 56 & 0.14 & 1.24 & \\
\hline Waist circumference & & & & & & & & & & & & & & & & & & & & \\
\hline Normal & 1144 & 80 & -0.02 & 1.02 & 0.000 & 948 & 80 & -0.05 & 1.03 & 0.000 & 768 & 80 & -0.17 & 1.05 & 0.000 & 621 & 81 & -0.29 & 1.03 & 0.000 \\
\hline Above & 282 & 20 & $2 \cdot 16$ & 0.59 & & 230 & 20 & $2 \cdot 10$ & 0.60 & & 189 & 20 & 1.94 & 0.67 & & 150 & 19 & 1.80 & 0.73 & \\
\hline
\end{tabular}

LONCAAFS, Longitudinal Study on Sedentary Behavior, Physical Activity, Dietary Habits and Health of Adolescents.

Bold values are significant $(P<0.05)$. 
Table 3 Association between BMI Z-score and dietary patterns scores of adolescents throughout the LONCAAFS study from 2014 to 2017 (generalised estimating equations)

\begin{tabular}{|c|c|c|c|c|c|c|c|c|}
\hline \multirow[b]{2}{*}{ Dietary pattern } & \multicolumn{2}{|c|}{ Model $1^{*}$} & \multicolumn{2}{|c|}{ Model 2† } & \multicolumn{2}{|c|}{ Model 3‡ } & \multicolumn{2}{|c|}{ Model $4 \S$} \\
\hline & $\beta$ & $95 \% \mathrm{Cl}$ & $\beta$ & $95 \% \mathrm{Cl}$ & $\beta$ & $95 \% \mathrm{Cl}$ & $\beta$ & $95 \% \mathrm{Cl}$ \\
\hline Traditional pattern & -0.016 & $-0.036,0.004$ & -0.018 & $-0.039,0.003$ & -0.013 & $-0.034,0.007$ & -0.013 & $-0.034,0.007$ \\
\hline Snacks pattern & -0.022 & $-0.041,-0.003$ & -0.024 & $-0.043,-0.003$ & -0.014 & $-0.033,-0.004$ & -0.014 & $-0.033,0.005$ \\
\hline Western pattern & 0.017 & $-0.003,0.038$ & 0.015 & $-0.008 ; 0.040$ & 0.024 & $0.001,0.050$ & 0.024 & $0.001,0.047$ \\
\hline
\end{tabular}

LONCAAFS, Longitudinal Study on Sedentary Behavior, Physical Activity, Dietary Habits and Health of Adolescents.

Bold values are significant $(P<0.05)$.

*Model 1: crude analysis model (Z-score of BMI and score of standards).

†Model 2: model adjusted for total energy.

¥Model 3: adjusted by the previous variables plus the variables sex, age and economic class.

$\S M o d e l$ 4: adjusted by the previous variables plus the variable level of physical activity.

positive relationship between Western diets at 5 and 7 years of age and overweight at 9 years of age ${ }^{(27)}$.

In this study, the foods that make up the 'Western' pattern have higher energy density, are rich in fats and sugars, and are low in fibre, and are associated with excess weight in adolescents ${ }^{(28-30)}$. In addition, foods classified as healthy and negatively associated with excess weight, such as fruits and vegetables, did not comprise any of the patterns identified in the present study, indicating that adolescents are replacing healthy eating habits with Western dietary patterns ${ }^{(31-33)}$. These eating behaviours are often associated with unfavourable health outcomes ${ }^{(34,35)}$.

Although the mean BMI $Z$-score was reduced for both sexes, this reduction was less intense among female adolescents, especially in the two final years of the study (2016 and 2017). This result was similar to that found in another study performed in England ${ }^{(36)}$, which reported that with increased age, the $Z$-scores of BMI and body fat were higher in girls. A study performed using data from the National Health and Nutrition Examination Survey, which prospectively analysed the BMI of participants from childhood to adolescence, also found a stabilisation in the prevalence of high BMI in girls but not in boys ${ }^{(37)}$.

Weight gain among girls tends to occur more rapidly than in boys, with a peak in weight gain occurring between 10 and 14 years of age, thereafter continuing, but at a reduced rate ${ }^{(38-41)}$. Due to the presence of sex hormones during puberty, girls tend to accumulate more fat than boys, due to the development of the buttocks, breasts and hips $^{(42-44)}$. Furthermore, girls usually reach their peak height after 13 years of age, whereas boys initiate their growth spurt at this age ${ }^{(38-41)}$. Thus, at the age of 14 years, boys tend to grow taller, with less weight gain and less fat, than girls, which may explain, in part, the greater BMI $Z$-scores among female adolescents.

Throughout the study, the proportion of adolescents with sedentary behaviour and their mean BMI $Z$-score decreased. A Brazilian study that used the data from the Pelotas cohort found that an increase in BMI was also found among adolescents who had increased sedentary behaviour, indicating a positive association between sedentary behaviour and BMI during adolescence ${ }^{(45)}$. In addition, a recent review showed that the majority of studies presented a risk association between sedentary behaviour and nutritional status in adolescents ${ }^{(46)}$.

This study has some limitations. First, the adherence to a dietary pattern may be influenced by cultural, family, seasonal, geographic and socio-economic factors, which can produce different patterns, formed by different food groups, and complicate the interpretation and comparison among the studies ${ }^{(47-51)}$. However, a recent systematic review showed that despite the differences in the studies analysed, they reported a similarity in the groups of foods that compose the dietary patterns of adolescents, which are considered unhealthy ${ }^{(11)}$. Second, the statistical method used to define the dietary patterns has subjective components, including the consolidation of food items in the food groups, the number of factors to extract and the labelling of standard $^{(52)}$. Thus, it remains a challenge to interpret and compare studies involving dietary patterns.

Despite these limitations, the analysis of food consumption by food patterns was carried out simultaneously, with complex combinations of nutrients ${ }^{(53-56)}$, which provided an approach to the effect of the combination of foods and nutrients on the nutritional status of adolescents ${ }^{(8,9)}$.

\section{Conclusions}

This analysis of adolescents in Brazil indicates that adherence to a 'Western' dietary pattern, composed of foods with high energy density, high fat and sugars, and low fibre, influences the BMI $Z$-score of adolescents. In addition, this study suggests the need to implement strategies to prevent and manage excessive weight and to encourage and support the diet and healthy behaviours of adolescents, regardless of nutritional status.

\section{Acknowledgements}

Acknowledgements: The authors gratefully acknowledge all of the children, their parents, schools and members participated in the LONCAAFS study. Financial support: This research was funded by the São Paulo Research 
Foundation (FAPESP), which granted Adélia da Costa Pereira de Arruda Neta a doctoral scholarship (proc. 2016/16551-4). Conflict of interest: There are no conflicts of interest. Authorship: A.C.P.A.N.: formal analysis, methodology, validation, visualisation, writing - original draft, and writing review and editing; J.C.F. Junior: data curation, methodology, validation, visualisation, and writing - review and editing; F.E.L.L.F.: data curation, methodology, validation, visualisation, and writing - review and editing; D.M.M.: formal analysis, methodology, validation, visualisation, writing - original draft, and writing - review and editing. Ethics of human subjectparticipation: This study was conducted according to the guidelines laid down in the Declaration of Helsinki and all procedures involving research study participants were approved by the Committee for Ethics in Research with Human Beings at the Health Sciences Center of the Federal University of Paraiba (registration no. 15268213 .0.0000.5188). Written informed consent was obtained from all subjects/patients.

\section{Supplementary material}

For supplementary material accompanying this paper visit https://doi.org/10.1017/S1368980021000252

\section{References}

1. World Health Organization (2015) Guideline Development Meeting on Preventing Obesity in Children and Adolescents through Appropriate Infant and Child Feeding Practices. Geneva: WHO.

2. Bloch KV, Klein CH, Szklo M et al. (2016) ERICA: prevalences of hypertension and obesity in Brazilian adolescents. Rev Saude Publica 50, 9s.

3. Willett WC, Howe GR \& Kushi LH (1997) Adjustment for total energy intake in epidemiologic studies. Am J Clin Nutr 65 , 1220S-1228S

4. Andrade RG, Pereira RA \& Sichieri R (2003) Food intake in overweight and normal-weight adolescents in the city of Rio de Janeiro. Cad Saúde Pública 19, 1485-1495.

5. World Health Organization (2003) Diet, Nutrition and the Prevention of Chronic Diseases. Geneva: WHO.

6. Risk factor collaboration - NCD-RisC (2017) Worldwide trends in body-mass index, underweight, overweight, and obesity from 1975 to 2016: a pooled analysis of 2416 population-based measurement studies in 128.9 million children, adolescents, and adults. Lancet 390, 2627-2642.

7. The NS, Suchindran C, North KE et al. (2010) Association of adolescent obesity with risk of severe obesity in adulthood. JAMA 304, 2042-2047.

8. Kristiansen AL, Lande B, Sexton JA et al. (2013) Dietary patterns among Norwegian 2-year-olds in 1999 and in 2007 and associations with child and parent characteristics. Br J Nutr 110, 135-144.

9. Azevedo ECC, Diniz AS, Monteiro JS et al. (2014) Dietary risk patterns for non-communicable chronic diseases and their association with body fat - a systematic review. Cien Saude Colet 19, 1447-1458.

10. Borges CA, Marchioni DML, Levy RB et al. (2018) Dietary patterns associated with overweight among Brazilian adolescents. Appetite 121, 8 .
11. Cunha C, Costa P, De Oliveira L et al. (2018) Dietary patterns and cardiometabolic risk factors among adolescents: systematic review and meta-analysis. BrJ Nutr 119, 859-879.

12. Verly E Jr, Castro MA, Fisberg RM et al. (2012) Precision of usual food intake estimates according to the percentage of individuals with a second dietary measurement. Acad Nutr Diet 112, 1015-1020.

13. Hair JF, Anderson RE, Tatham RL et al. (2009) Multivariate Data Analysis. Porto Alegre: Editora Bookman.

14. Biazzi Leal D, Altenburg de Assis MA, Hinnig PF et al. (2017) Changes in dietary patterns from childhood to adolescence and associated body adiposity status. Nutrients 9, E1098.

15. Movassagh EZ, Baxter-Jones ADG, Kontulainen S et al. (2017) Tracking dietary patterns over 20 years from childhood through adolescence into young adulthood: the Saskatchewan pediatric bone mineral accrual study. Nutrients 9, E990.

16. Lohman T, Roache A \& Martorell R (1992) Anthropometric standardization reference manual. Med Sci Sports Exerc 24, 952.

17. World Health Organization (2006) Multicentre Growth Reference Study Group. WHO Child Growth Standards: Length/Height-for-Age, Weight-for-Age, Weight-for-Length, Weight-for-Height and Body Mass Index-for-Age: Methods and Development. Geneva: WHO.

18. ABEP - Brazilian Association of Research Companies (2012) Economic classification criteria Brazil. http://www.abep.org (accessed September 2019).

19. Farias Júnior JC, Lopes AS, Mota J et al. (2012) Validity and reproducibility of a physical activity questionnaire for adolescents: adapting the self-administered physical activity checklist. Rev Bras Epidemiol 15, 198-210.

20. Prazeres Filho A, Barbosa AO, Mendonça G et al. (2017) Reproducibility and concurrent validity of the physical activity questionnaire for adolescents (QAFA) aged 10-14 years. Rev Bras Cineantropom Desempenho Hum 19, 270-282.

21. World Health Organization (2010) Global recommendations on physical activity for health. http://www.who.int/dietphysical activity/factsheet_recommendations/en/ (accessed July 2019).

22. American Academy of Pediatrics (2001) Children, adolescents, and television. Pediatrics 107, 423-426.

23. Alves MA, Souza AM, Barufaldi LA et al. (2019) Dietary patterns of Brazilian adolescents according to geographic region: an analysis of the study of cardiovascular risk in adolescents (ERICA). Cad Saúde Pública 35, e00153818.

24. Oellingrath IM, Svendsen MV \& Brantsaeter AL (2011) Tracking of eating patterns and overweight: a follow-up study of Norwegian schoolchildren from middle childhood to early adolescence. Nutr J 10, 106.

25. Field AE, Austin SB, Gillman MW et al. (2004) Snack food intake does not predict weight change among children and adolescents. Int J Obes Relat Metab Disord 28, 1210-1216.

26. Alexy U, Libuda L, Mersmann S et al. (2011) Convenience foods in children's diet and association with dietary quality and body weight status. Eur J Clin Nutr 65, 160-166.

27. Johnson L, Mander AP, Jones LR et al. (2008) Energy-dense, low-fiber, high-fat dietary pattern is associated with increased fatness in childhood. Am J Clin Nutr 87, 846-854.

28. Ambrosini GL, Huang RC, Mori TA et al. (2010) Dietary patterns and markers for the metabolic syndrome in Australian adolescents. Nutr Metab Cardiovasc Dis 20, 274-283.

29. Joung H, Hong S, Song Y et al. (2012) Dietary patterns and metabolic syndrome risk factors among adolescents. Korean J Pediatr 55, 128-135.

30. Romero-Polvo A, Denova-Gutierrez E, Rivera-Paredez B et al. (2012) Association between dietary patterns and insulin resistance in Mexican children and adolescents. Ann Nutr Metab 61, 142-150. 
31. Nielsen SJ \& Popkin BM (2003) Patterns and trends in food portion sizes, 1977-1998. JAMA 289, 450-453.

32. Monteiro CA, Gomes FS \& Cannon G (2010) The snack attack. Am J Public Health 100, 975-981.

33. Popkin BM (2011) Contemporary nutritional transition: determinants of diet and its impact on body composition. Proc Nutr Soc 70, 82-91.

34. Angelieri CT, Barros CR \& Siqueira-Catania A (2012) Trans fatty acid intake is associated with insulin sensitivity but independently of inflammation. Braz J Med Biol Res 45, 625-631.

35. Li Y, Hruby A, Bernstein AM et al. (2015) Saturated fats compared with unsaturated fats and sources of carbohydrates in relation to risk of coronary heart disease: a prospective cohort study. J Am Coll Cardiol 66, 1538-1548.

36. Ambrosini GL, Emmett PM, Northstone K et al. (2012) Identification of a dietary pattern prospectively associated with increased adiposity during childhood and adolescence. Int J Obes 36, 1299-1305.

37. Ogden CL, Carroll MD, Curtin LR et al. (2010) Prevalence of high body mass index in US children and adolescents, 2007-2008. JAMA 303, 242-249.

38. Forbes GB (1987) Human Body Composition. New York: Springer-Verlag.

39. Guo SS, Roche AF, Chumlea WC et al. (1994) The predictive value of childhood body mass index values for overweight at age 35. Am J Clin Nutr 59, 810-819.

40. Guo SS \& Chumlea WC (1999) Tracking of body mass index in children in relation to overweight in adulthood. Am J Clin Nutr 70, 145S-148S.

41. Siervogel RM, Roche AF, Guo SM et al. (1991) Patterns of change in weight/stature from 2 to 18 years: findings from long-term serial data for children in the Fels longitudinal growth study. IJO 15, 479-485.

42. Daniels SR, Arnett DK, Eckel RH et al. (2005) Overweight in children and adolescents. Pathophysiology, consequences, prevention, and treatment. Circulation 111, 1999-2012.

43. Rogol AD (2010) Sex steroids, growth hormone, leptin and the pubertal growth spurt. Endocr Dev 17, 77-85.

44. Rogol AD, Roemmich JN \& Clark PA (2002) Growth at puberty. J Adolescent Health 31, 192-200.

45. Dumith SC, Garcia LMT, Silva KS et al. (2012) Predictors and health consequences of screen-time change during adolescence - 1993 Pelotas (Brazil) birth cohort study. $J$ Adolesc Health 51, 16-21.

46. Guerra PH, Ribeiro EHC, Leme ACB et al. (2018) Sedentary behavior and body composition in children of low-and mid-income countries: a review. Rev Bras Ativ Fís Saúde 23, 02.

47. Pollard CM, Landrigan TJ, Ellies PL et al. (2014) Geographic factors as determinants of food security: a Western Australian food pricing and quality study. Asia Pac J Clin Nutr 23, 703-713.

48. Chi DL, Luu M \& Chu F (2017) A scoping review of epidemiologic risk factors for pediatric obesity: implications for future childhood obesity and dental caries prevention research. J Public Health Dent 77, S8-S31.

49. Manyanga T, Tremblay MS, Chaput JP et al. (2017) Socioeconomic status and dietary patterns in children from around the world: different associations by levels of country human development? BMC Public Health 17, 457.

50. Giskes K, Van Lenthe F, Avendano-Pabon M et al. (2011) A systematic review of environmental factors and obesogenic dietary intakes among adults: are we getting closer to understanding obesogenic environments? Obes Rev $\mathbf{1 2}$, e95-e106.

51. Fernández-Alvira JM, Börnhorst C, Bammann K et al. (2015) Prospective associations between socio-economic status and dietary patterns in European children: the identification and prevention of dietary- and lifestyle-induced health effects in children and infants (IDEFICS) study. Br J Nutr 113, 517-525.

52. Martinez ME, Marshall JR \& Sechrest L (1998) Invited commentary: factor analysis and the search for objectivity. Am J Epidemiol 148, 17-19.

53. Hu FB (2002) Dietary pattern analysis: a new direction in nutritional epidemiology. Curr Opin Lipidol 13, 3-9.

54. Kant AK (2004) Dietary patterns health outcomes. J Am Diet Assoc 104, 615-635.

55. Newby PK, Muller D, Hallfrisch J et al. (2003) Dietary patterns and changes in body mass index and waist circumference in adults. Am J Clin Nutr 77, 1417-1425.

56. Moeller SM, Reedy J, Millen AE et al. (2007) Dietary patterns: challenges and opportunities in dietary patterns research an Experimental Biology workshop. J Am Diet Assoc 107, 1233-1239. 